
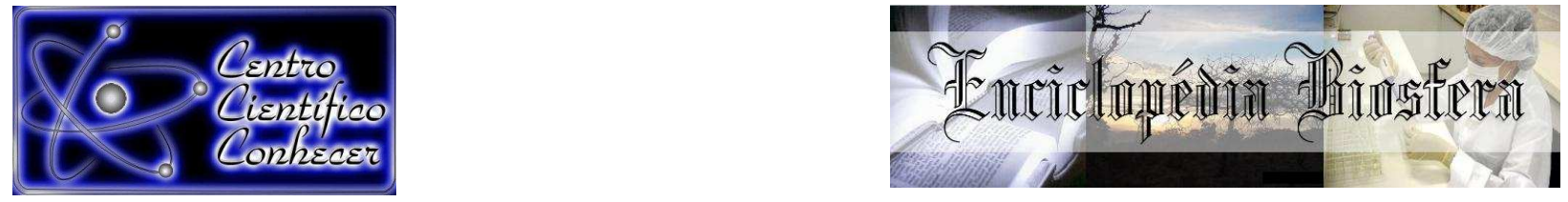

\title{
PRODUTIVIDADE E EFICIÊNCIA DO USO DE ÁGUA DA BANANEIRA CAIPIRA SOB DIFERENTES DENSIDADES DE PLANTIO E LÂMINAS DE IRRIGAÇÃO
}

\author{
Eugênio Ferreira Coelho ${ }^{1}$, Welson Lima Simões ${ }^{2}$, Fabricio Pedreira Santos ${ }^{3}$, Diego \\ Magalhães de Melo ${ }^{4}$, Lenilson Wisner Ferreira Lima ${ }^{5}$ \\ 1 Doutor, Pesquisador da EMBRAPA Mandioca e Fruticultura \\ (Eugenio.coelho@embrapa.br) Cruz das Almas-Brasil. \\ 2 Doutor, Pesquisador da EMBRAPA Semi Árido. \\ 3 Graduando em Agronomia da Universidade Federal do Recôncavo da Bahia. \\ 4 Eng. Agrônomo Mestrando. Engenharia Agrícola, da Universidade Federal do \\ Recôncavo da Bahia \\ 5 Eng. Agrônomo Msc. Engenharia Agrícola.
}

Recebido em: 08/09/2015 - Aprovado em: 14/11/2015 - Publicado em: 01/12/2015

DOI: http://dx.doi.org/10.18677/Enciclopedia_Biosfera_2015_214

\begin{abstract}
RESUMO
O aumento da eficiência de uso de água (EUA) pode ser conseguido pela redução da transpiração das plantas, como pelo aumento da produtividade para a mesma quantidade de água evapotranspirada pela cultura. O objetivo do trabalho foi avaliar a resposta da bananeira cultivar Caipira a quatro níveis de água sob duas densidades de plantio no primeiro ciclo. As variáveis analisadas foram altura da planta, circunferência do pseudocaule a $0,30 \mathrm{~m}$ do solo, área foliar a partir do comprimento, largura da terceira folha e número de folhas. Durante a colheita foram avaliados: rendimento, peso de pencas, comprimento, diâmetro médio, peso de fruto (dedo central da segunda penca), e a EUA. O delineamento experimental foi em blocos casualizados com quatro repetições, seguindo um esquema em parcelas subdivididas com a densidade de plantas (um e dois seguidores por touceira) na parcela e o nível de água aplicado na subparcela (lâmina com base na ETc e 85\%, $70 \%$ e $50 \%$ da ETc). A redução na aplicação de água de irrigação em até $30 \%$ da quantidade recomendada não trouxe reduções significativas na produtividade da bananeira cultivar Caipira. A condução de dois seguidores por touceira não diferiu da condução do bananal com um seguidor, em termos de crescimento e produtividade.
\end{abstract}

PALAVRAS-CHAVE: Evapotranspiração, manejo de irrigação, microaspersão

\section{YIELD AND WATER USE EFFICIENCY OF BANANA CV CAIPIRA UNDER DIFFERENT PLANT DENSITY IRRIGATION WATER DEFICITS}

\begin{abstract}
The increase in water use efficiency (WUE) may be accomplished by plant transpiration reduction as well by the increase in yield for the same amount of evapotranspiration water by crop. The objective of the work was to evaluate the response of banana cv Caipira to four levels of water under two planting densities during the first cycle.. The experiment design followed a random block design with four replications, in a split plot scheme. The plant density (one and two plants per bunch) in the plot and the level of water in the subplot (water depth based upon:ETc
\end{abstract}


and $85 \%, 70 \%$ and $50 \%$ ETc). The reduction of $30 \%$ on the recommended water depth did not bring significant reductions to yield of banana cv Caipira. The use of two plants per bunch did not differ from the use of a single plant per bunch concerning growth and yield.

KEYWORDS: Evapotranspiration, irrigation schedule, microsprinkler.

\section{INTRODUÇÃO}

A banana apresentou no ano de 2013 uma produção mundial de 106 milhões de toneladas, deste total a Ásia produziu 56,44\% e a América $25,29 \%$, sendo o Brasil responsável por $6,46 \%$ da produção mundial, com um rendimento de 14,05 ton.ha ${ }^{-1}$ (FAO, 2013). No Brasil a região nordeste se destaca como sendo a região com maior produção e dentre os estados a Bahia (IBGE, 2013).

Os recursos hídricos cada vez mais escassos limitam, de modo geral, a prática da irrigação na agricultura, que apesar de existir estudos destinados ao manejo sustentável da água na cultura da banana, são ainda restritos relatos destas informações (MELO et al. 2010). No entanto, a geração de conhecimentos que tenham validade e comprovação local visando obter melhorias tecnológicas para cada situação de cultivo torna-se imprescindíveis (COSTA et al. 2012).

As constantes incertezas climáticas ou à distribuição irregular de chuvas, tem aumentado o número de usuários da irrigação, o que demanda conhecimento das reais necessidades hídricas da cultura (COELHO et al. 2013). A utilização da técnica da irrigação, além da possibilidade de produzir com margem de segurança, esta prática resulta em frutos com melhores qualidades e aumento significativos na produtividade em, pelo menos, 40 \% quando comparada à ausência de irrigação (COELHO et al. 2006).

Considerando a água como um insumo, e as áreas agrícolas restritas à sua expansão, a agricultura mundial tende a aperfeiçoar o uso dos recursos naturais, especialmente, a água e o solo (PAMPONET et al. 2012). Neste sentido, torna-se imprescindível o aumento da eficiência do uso de água (EUA) que consiste basicamente na razão entre a produtividade de uma cultura e o consumo de água da mesma (LOOMIS, 1983), podendo a EUA aumentar com a redução da lâmina aplicada sem diminuição da produção com economia de água e aumento dos lucros (MELO et al. 2010; TEIXEIRA et al., 2011; OLIVEIRA et al., 2013).

O aumento de produtividade para a mesma lâmina aplicada também aumenta a EUA, o que pode ocorrer atuando-se no manejo da cultura, aumentando a densidade de plantas, adubação e tratos culturais. BELALCÁZAR CARVAJAL (1991) em trabalho com densidade de plantio de bananeira mostrou que o maior ou menor rendimento do bananal dependerá tanto do espaçamento quanto do número de seguidores da planta mãe. O principal fator limitante sobre a cultura da banana com densidade de plantas elevada é a luz do sol, efeitos de floração, duração do cultivo, da maturidade e desempenho dos cachos (BISWAS \& LALIT KUMAR, 2010).

A resposta da cultura da bananeira a diferentes níveis de irrigação depende de diversos fatores tais como condições meteorológicas locais que resultam em diferentes condições de evapotranspiração e constante térmica, associados às características dos genótipos (COELHO et al., 2006). TURNER (1994) relata que dentro do grupo genômico (AAA), grupo da variedade Caipira, existem diferenças entre as variedades quanto à tolerância ao estresse hídrico. Os trabalhos que avaliam necessidades hídricas da bananeira têm sido relacionados ao manejo da cultura com uma planta por touceira (AZEVEDO \& BEZERRA, 2008; SANTANA et al., 2012; COSTA et al., 2012). 
Há necessidade de avaliar os efeitos do aumento de densidade de plantas na produtividade da cultura da bananeira, para as condições irrigadas, de forma aumentar a eficiência de uso de água pela cultura da bananeira. Alguns produtores de banana cultivam a bananeira com mais de um seguidor por família, mas de forma não sistemática, com um número elevado de seguidores, sem os cuidados ou tratos culturais necessários, contribuindo para a redução da longevidade do bananal. A adequação do numero de seguidores as condições hídricas do solo pode contribuir para aumento da produtividade, com uso racional de água.

O presente trabalho teve como objetivo avaliar a resposta da bananeira Caipira a quatro níveis de água sob duas densidades de plantio no primeiro ciclo.

\section{MATERIAL E MÉTODOS}

O experimento foi conduzido no município de Jaíba, localizado na região semi-árida do Norte de Minas Gerais, nos campos experimentais da Empresa de Pesquisa Agropecuária de Minas Gerais-Epamig. O clima da região, segundo a classificação de Köppen, é do tipo BSwh (clima quente de caatinga), com chuvas de verão e períodos secos bem definidos no inverno. A cultura utilizada foi da bananeira, cultivar Caipira, implantada em fileiras simples no espaçamento de 3,0 m x 2,7 m, irrigada por microaspersão, com um emissor de vazão $70 \mathrm{~L} / \mathrm{h}$ para quatro plantas.

O solo da área experimental é de classificação textural franco arenoso, com o teor de água do solo equivalente ao limite superior da disponibilidade de água do solo $(-10 \mathrm{kPa})$ de $0,2047 \mathrm{~cm}^{3} / \mathrm{cm}^{3}$ e o teor de umidade equivalente ao limite inferior da disponibilidade de água do solo $(-1500 \mathrm{kPa})$ de $0,1345 \mathrm{~cm}^{3} / \mathrm{cm}^{3}$.

O delineamento experimental foi em blocos casualizados com quatro repetições, seguindo um esquema em parcelas subdivididas com a densidade de plantas na parcela e o nível de água aplicado na subparcela. Os níveis de água foram estabelecidos em função dos níveis que corresponderam à máxima produtividade física em trabalhos realizados na região conforme Coelho et al. (2006).

Para o cálculo do volume de água aplicado em cada irrigação, a ETc foi determinada pelo produto da evapotranspiração potencial (ETo) obtida por uma estação meteorológica automática instalada próximo do local e do coeficiente de cultura (Kc), conforme COELHO et al. (2006), obtidos para a região. Com base nesse valor calculado, obtiveram-se os volumes de água relativos aos tratamentos referentes às lâminas de água aplicadas, isto é, a equivalente a ETc calculada (lâmina de referência ou testemunha - T1) e as equivalentes a $85 \%, 70 \%$ e $50 \%$ da lâmina de referencia.

As densidades de plantas foram resultantes da condução de uma e duas plantas por touceira, isto é, uma planta seguidora da anterior (1P) e duas plantas seguidoras (2P). Nesse caso as densidades de plantas foram de 1234 e 2469 plantas/ha, mantendo-se o mesmo número touceiras nos dois casos (1234 touceiras/ha).

A diferenciação dos tratamentos foi através de registros instalados no inicio da área experimental, cada um correspondente a um tratamento (combinação de número de seguidores e lâmina de irrigação). Foi realizado o monitoramento do potencial matricial do solo com as leituras feitas no início da manhã a $0,50 \mathrm{~m}$ da planta na direção do microaspersor, a uma profundidade de $30 \mathrm{~cm}$, numa frequência de 2 dias.

Cada parcela foi avaliada a partir de seis plantas úteis, onde foram medidos a altura da planta, circunferência do pseudocaule a $0,30 \mathrm{~m}$ do solo, área foliar a partir 
do comprimento e largura da terceira folha segundo ALVES et al. (2001) e número de folhas. Durante a colheita foram avaliados: rendimento, peso de pencas, comprimento, diâmetro médio, peso de fruto (dedo central da segunda penca) e eficiência de uso da água. Os dados foram submetidos a análise de variância sendo que foi empregada análise de regressão para lâminas.

\section{RESULTADOS E DISCUSSÃO}

A evapotranspiração de referencia acumulada no período de 29/04/2005 a 17/04/2006 foi de $960 \mathrm{~mm}$, sendo que a evapotranspiração total da cultura foi de 753 $\mathrm{mm}$. As lâminas bruta aplicada no período equivalentes a total evapotranspirada (ETc), $85 \%, 70 \%$ e $50 \%$ da ETc foram de 647, 551, 454 e $329 \mathrm{~mm}$, respectivamente.

A análise de variância mostrou que o número de seguidores por touceira, isto é a densidade de plantas não teve efeito sobre a maioria das variáveis de crescimento e de produtividade da bananeira $(P>0,10)$. A lâmina de irrigação aplicada teve influência apenas na variável na altura da planta entre as variáveis de crescimento da bananeira. A regressão aplicada a essa variável não demonstrou tendência dessa em função da lâmina aplicada. A altura média de plantas obtida sob a lâmina $329 \mathrm{~mm}$ diferiu da média sob a lâmina de $647 \mathrm{~mm}$, cuja média foi superior a verificada naquela lâmina. Com respeito ao número de folhas, a análise de variância foi significativa apenas para efeito da lâmina de irrigação nessa variável, sendo que o menor número de folhas equivaleu a menor lâmina aplicada e vice-versa (Tabela 1). No caso da área foliar, não houve efeito do número de seguidores por touceira (densidade de plantas), bem como das lâminas aplicadas nessa variável, embora, em valores absolutos, tenha havido desvio de até $25,6 \%$ em relação a lâmina máxima aplicada (equivalente a ETc). O diâmetro de caule também não foi influenciado pela densidade de plantas ou pela lâmina de irrigação aplicada. Não houve efeito da interação lâmina $x$ densidade de plantas em qualquer variável de crescimento.

TABELA 1. Parâmetros de crescimento da bananeira Caipira sob duas densidades e quatro níveis de irrigação

\begin{tabular}{ccccc}
\hline $\begin{array}{c}\text { Lâmina } \\
(\mathrm{mm})\end{array}$ & $\begin{array}{c}\text { Número de } \\
\text { folhas }\end{array}$ & $\begin{array}{c}\text { Diâmetro de } \\
\text { caule } \\
(\mathrm{m})\end{array}$ & $\begin{array}{c}\text { Altura de } \\
\text { plantas } \\
(\mathrm{m})\end{array}$ & $\begin{array}{c}\text { Área foliar } \\
\left(\mathrm{m}^{2}\right)\end{array}$ \\
\hline 329 & 6,1 & 0,14 & 1,7 & 6,45 \\
454 & 7,2 & 0,15 & 2,0 & 7,49 \\
551 & 6,5 & 0,15 & 2,0 & 7,64 \\
647 & 7,0 & 0,15 & 2,8 & 8,68 \\
\hline
\end{tabular}

Os resultados de crescimento indicaram indiferença das variáveis entre as duas densidades de plantas, o que não foi concordante com BELALCÁZAR CARVAJAL (2002) que trabalhando com densidade de plantio da bananeira Dominico-Hartón (Musa AAB Simmonds) com uma planta, duas e três por cova verificaram influência da densidade populacional no crescimento, sendo maior o crescimento para maior a densidade populacional.

As variáveis de qualidade física do fruto (diâmetro e comprimento) não foram influenciadas pela densidade ou pelas lâminas aplicadas. $O$ peso de pencas não foi influenciado pela densidade de plantas, mas pela lâmina aplicada e pela interação lâminas $x$ densidade. $O$ desdobramento da lamina dentro de cada densidade de plantas mostrou um comportamento quadrático da produtividade de pencas com a 
lâmina aplicada. A produtividade máxima física de pencas para a densidade de 1234 plantas ha ${ }^{-1}$ ocorreu para a lâmina de $505,7 \mathrm{~mm}$, sendo de $19,2 \mathrm{t} \mathrm{ha}^{-1}$, superior a produtividade máxima registrada para a densidade de 2469 plantas de $15,6 \mathrm{t} \mathrm{ha}^{-1}$ correspondente a uma lâmina aplicada de $571,9 \mathrm{~mm}$. Esse resultado indica que dobrando a densidade da cultivar Caipira houve uma maior competição por água do solo, o que pode ser observado pelas lâminas que maximizam a produtividade, isto é, houve maior necessidade de água no caso de duas plantas por touceira para se atingir a produtividade máxima que no caso de uma planta por touceira. Essa competição no caso de duas plantas por touceira influenciou a produtividade.

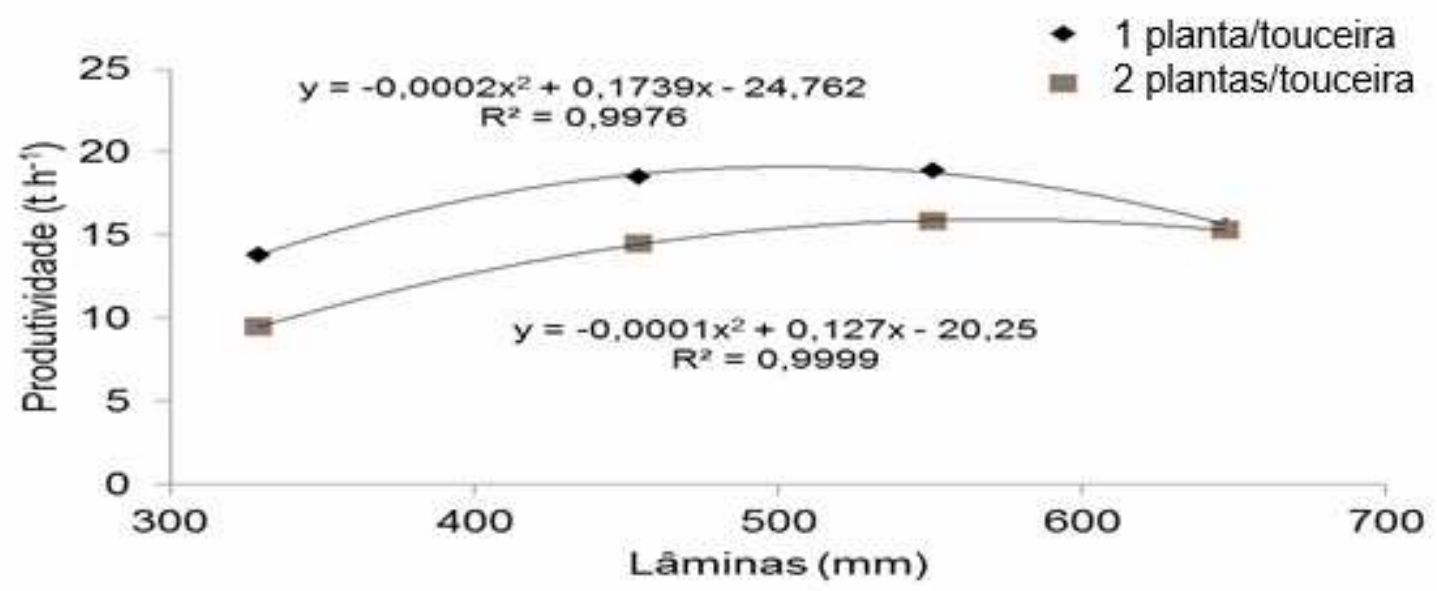

FIGURA 1. Produtividade em função das lâminas aplicadas para uma e duas plantas por touceira.

Os resultados mostram que a redução da lâmina de irrigação de $647 \mathrm{~mm}$ para $454 \mathrm{~mm}$, isto é, $42 \%$ não promove diferenças significativas na produtividade da bananeira cv, Caipira tanto para um como para dois seguidores por touceira, isto é, a redução de $193 \mathrm{~mm}$ ou $1930 \mathrm{~m}^{3}$.ha ${ }^{-1}$ não acarretou diferença na produtividade para as duas densidades de plantas. $\mathrm{O}$ uso de dois seguidores por touceira implicou em uma produtividade média inferior a obtida com um seguidor no primeiro ciclo.

A EUA seguiu as produtividades tendo sido inferior para a condução de dois seguidores em todos os tratamentos com redução de lâmina irrigada.

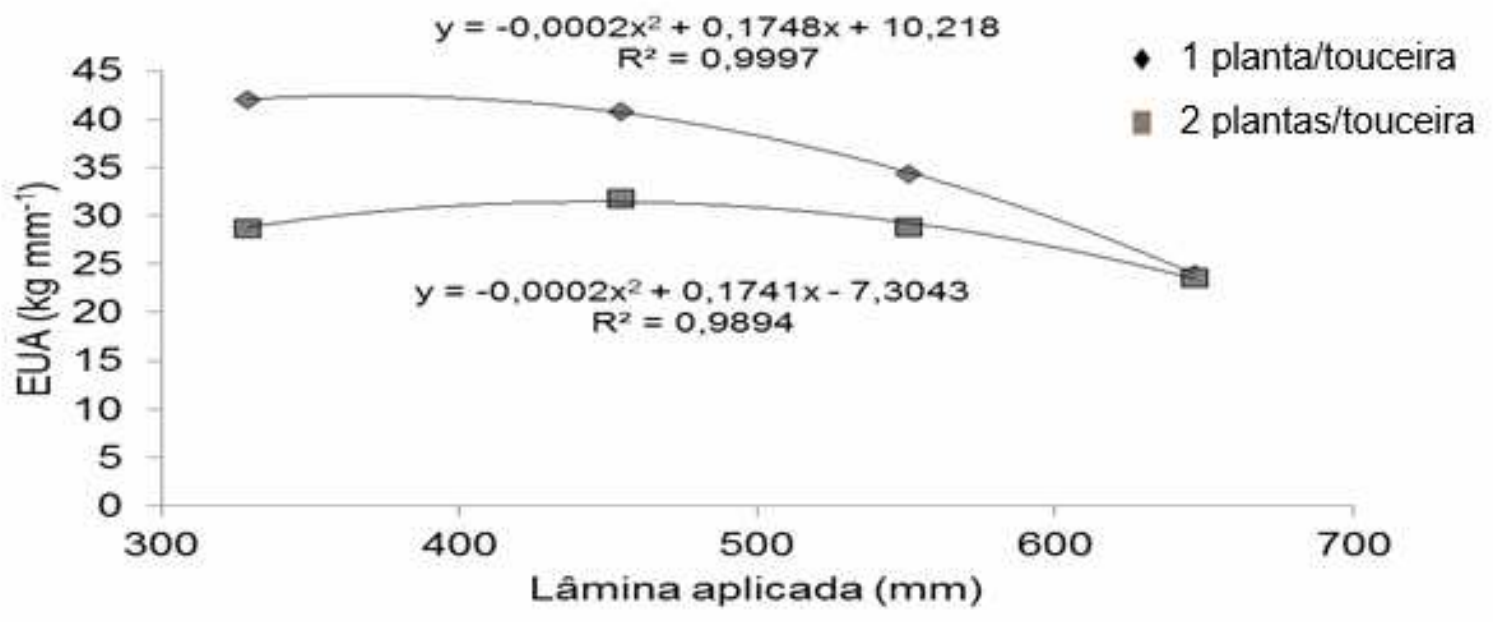

FIGURA 2. Eficiência de uso de água em função das lâminas aplicadas para uma e duas plantas por touceira. 
A EUA foi máxima para a menor lâmina aplicada para a densidade de uma planta por touceira, entretanto, para a densidade de duas plantas por touceira a lamina de máxima EUA foi superior, isto é, de $435,2 \mathrm{~mm}$, valor esse próximo do valor da lâmina equivalente a máxima produtividade. Dessa forma, mesmo com uma lâmina superior, a proximidade da produtividade máxima favorece essa condição em relação a uma planta por touceira, onde apesar de máxima EUA, a produtividade equivalente é muito menor que a produtividade máxima.

No caso da irrigação testemunha, não houve redução nem na produtividade, nem na EUA indicando que a condução de dois seguidores com os níveis de água recomendados não difere de se usar um seguidor no primeiro ciclo da cultura. No primeiro ciclo foi colhido apenas um pseudocaule por touceira em todos os tratamentos. Possivelmente houve maior demanda de água nas touceiras com dois seguidores. Apesar da variabilidade dos valores de tensão observados em todas as subparcelas de diferentes lâminas, as tensões máximas são maiores para as subparcelas com dois seguidores (Figura 3). A media de todas as tensões observadas para as subparcelas $(25,42 \mathrm{kPa})$ com dois seguidores também é superior em valor absoluto à média das tensões verificadas nas subparcelas com um seguidor $(24,42 \mathrm{kPa})$. Esses resultados mostram que para a mesma lâmina aplicada, houve maior extração nas subparcelas com duas famílias e consequentemente maior estresse hídrico no solo nesse caso confirmando os resultados de produtividade.

(A) Um seguidor por touceira

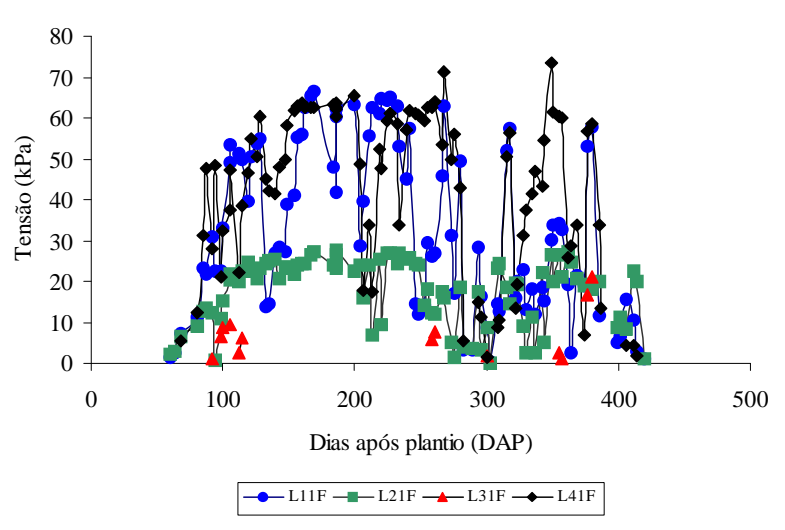

(B) Dois seguidores por touceira

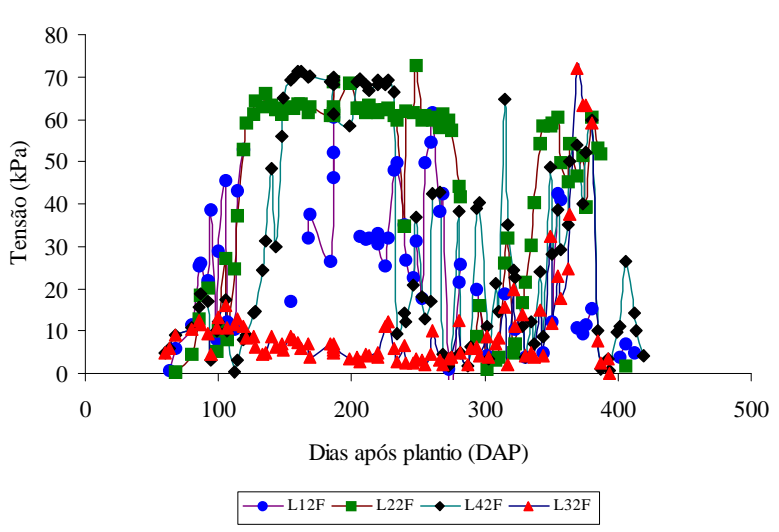

FIGURA 3. Tensão de água no solo para as diferentes lâminas de irrigação aplicadas nas duas densidades de plantas.

\section{CONCLUSÔES}

Não houve redução da produtividade ou da eficiência de uso de água para a aplicação da lâmina de irrigação recomendada para a condução de um ou dois seguidores no primeiro ciclo.

A redução na aplicação de água de irrigação em até $42 \%$ da quantidade recomendada não trouxe reduções significativas na produtividade da bananeira cv. Caipira.

O cultivo com dois seguidores demanda maior extração de água do solo. 


\section{AGRADECIMENTOS}

Ao CT-Hidro/CNPq pelo suporte financeiro. Aos técnicos e funcionários da fazenda Experimental de Mocambinho pela dedicação durante a execução do experimento e a Empresa de Pesquisa Agropecuária de Minas Gerais, pela parceria.

\section{REFERÊNCIAS}

ALVES, A. A. C. ; SILVA JÚNIOR, J. F. S. ; COELHO, E. F. . Estimation of banana leaf area by simple and non-destructive methods. In: VIII Congresso Brasileiro de Fisiologia Vegetal, 2001, Ilhéus. Anais. Ilhéus : Sociedade Brasileira de Fisiologia Vegetal, 2001. p. 3p

BELALCAZAR CARVAJAL, S.L. El cultivo de plátano em el trópico. Cáli, Colômbia: Impresora Feriva, 1991. 376p.

BELALCÁZAR C., S. Altas densidades de siembra en plátano, uma alternativa rentable y sostenible de producción. Medelin, Acorbat. XV reunión. Colombia. 2002.

BISWAS, B.C. \& LALIT KUMAR, F., N. D. High Density Planting: Success Stories of Banana Farmers. Fertiliser Marketing News, v. 41 (6), pp.3-10(8 pages). Jun/ 2010.

COELHO, E. F. ; COSTA, E. L. ; LEDO, C. A. da S. ; SILVA, S. O. Produtividade e eficiencia do uso de água das bananeiras Prata Anã e Grand Nine no terceiro ciclo no Norte de Minas. Irriga (Botucatu), v. 11, p. 460-468, 2006.

COELHO, E. F.; OLIVEIRA, R. C.; PAMPONET, A. J. M. Necessidades hídricas de bananeira tipo Terra em condições de tabuleiros costeiros. Pesq. agropec. bras., Brasília, v.48, n.9, p.1260-1268, set. 2013.

COSTA, F. S., SUASSUNA, J. F., MELO, A. S., BRITO, M. E. B., MESQUITA, E. F. Crescimento, produtividade e eficiência no uso da água em bananeira irrigada no semiárido paraibano. Revista Caatinga, Mossoró, v. 25, n. 4, p. 26-33, out-dez., 2012

COSTA, F. S.; COELHO, E. F.; BORGES, A. L.; PAMPONET, A. J. M.; SILVA, A. A. S. M.;AZEVEDO, N. F. Crescimento, produção e acúmulo de potássio em bananeira 'Galil 18 ' sob irrigação e fertilização potássica. Pesq. agropec. bras., Brasília, v.47, n.3, p.409-416, mar. 2012.

LOOMIS, R. S. Crop manipulations for efficient use of water: An overview. In: TAYLOR, H. M.; JORDAN, W. R.; SINCLAIR, T. R. Limitations to efficient water use in crop production. (ed). American Society of Agronomy, Crop Society of America, and Soil Science Society of America, Madison WI . p. 345-374, 1983.

MOREIRA, R. S. Banana: Teoria e Prática. Fundação Cargill, 2 ed. São Paulo, SP, CDrom. 
MELO, A. S., Suassuna, J. F., Fernandes, P. D., Brito, M. E. B., Suassuna, A. F., Aguiar Netto, A. O. Crescimento vegetativo, resistência estomática, eficiência fotossintética e rendimento do fruto da melancieira em diferentes níveis de água. Acta Scientiarum Agronomy, Maringá, v. 32, n. 1, p. 73-79, 2010.

OLIVEIRA, J. M.; COELHO FILHO, M.A.; COELHO, E.F. Crescimento da bananeira Grande Naine submetida a diferentes lâminas de irrigação em tabuleiro costeiro. Revista Brasileira de Engenharia Agrícola e Ambiental, v.17, n.10, p.1038-1046, 2013.

PAMPONET, A. J. M., AMORIM, M. S., ANDRADE, T. P. COELHO, E.F., SILVA, A. C. P. Produtividade da bananeira $\mathrm{cv}$. prata anã no terceiro ciclo submetido a diferentes lâminas de irrigação e densidades de plantas. Congreso Latinoamericano y del Caribe de Ingeniería Agrícola e XLI Congresso Brasileiro de Engenharia Agrícola CLIA/CONBEA 2012. Londrina - PR, Brasil, 15 a 19 de julho 2012.

SANTANA, j. a. v.; COELHO, E. F.; FARIA, M. A.; SILVA, E. L. RODRIGUES, S. L. Distribuição de raízes de bananeira 'Prata-Ana' no segundo ciclo de produção sob três sistemas de irrigação. Rev. Bras. Frutic., Jaboticabal, SP, v. 34, n. 1, p. 124133,Mar.,2012.

TEIXEIRA, L. A. J.; QUAGGIO, J. A.; MELLIS, E.V. Ganhos de eficiência fertilizante em bananeira Sob irrigação e fertirrigação. Revista brasileira de Fruticultura, Jaboticabal-SP, Vol. 33. n9, p. 272-278, Mar. 2011.

TURNER, W. D. Bananas and Plantains. In: SCHAFFER, B. \& ANDERSEN, P. C. Handbook of environmental physiology of fruits. Vol. II: Sub-tropical and tropical crops. 1994, p. 37-64, 316 p. 